\title{
TOXIC THROMBOCYTOPENIC PURPURA FOLLOWING LOCAL SULPHATHIAZOLE THERAPY
}

\author{
BY \\ G. M. DONALDSON AND HAROLD SCARBOROUGH
(From the Department of Medicine, Edinburgh University and the Clinical Laboratories, the Royal Infirmary, Edinburgh)

In spite of the universal use of sulphonamides there have apparently been reports of the occurrence of purpura following their administration on only twenty-two occasions. In fourteen cases the thrombocytes were found to be reduced in number, absent from blood films or below 100,000 per c.mm.; in four cases the thrombocyte count exceeded 125,000 per c.mm. and in four the count was not recorded. In all cases the drug was given by mouth and the amount producing purpura varied between 4 and $45 \mathrm{gm}$. In six cases purpura followed interrupted administration, the interval varying between one day and three years. The literature on the subject has recently been referred to more fully by Sherlock and White (1944). The case here reported is of interest in that thrombocytopenic purpura followed the local application of a 5 per cent. sulphathiazole ointment, and for the light which the investigations throw upon the mechanism of the condition.

\section{Case history}

A. M., a boy, aged twelve years, was admitted to hospital on October 27, 1943. Four days previously a few small areas of impetigo were noticed on the face and on the right foot. An ointment containing 5 per cent. sulphathiazole was applied to these areas twice daily for two days. On the evening of the second day his nose began to bleed and a purpuric rash appeared on his body. He was admitted to hospital the following morning. He had previously been a healthy child and there was nothing of note in his personal or family medical history. There was no evidence of allergic manifestations or of any haemorrhagic diathesis in himself or in any of his relatives. He had never had sulphonamide drugs before.

On examination he was a sturdy well-nourished child. The temperature was $98 \cdot 6^{\circ} \mathrm{F}$. There was profuse bleeding from both nostrils. The lips, around which the sulphathiazole ointment had been applied, were swollen and blood was oozing from them freely. There was no bleeding from the gums and no visible submucous purpura in the mouth. The whole of his body, including the face and limbs, was covered with a purpuric rash, the haemorrhagic areas varying between $1 \mathrm{~mm}$. and $1 \mathrm{~cm}$. in size. There were no large ecchymoses and no retinal haemorrhages. There was no blood in the urine but occult blood was present in the stool. The liver and spleen were not clinically enlarged, but enlarged glands in the axillae and neck were palpable without tenderness. Three small areas of impetigo, each approximately the size of a sixpennypiece, were noted on the face and right leg.

EXAMINATION OF THE BLOOD immediately on admission to hospital gave the following results:R.B.C. $4 \cdot 12$ million per c.mm.; Hb. $11 \cdot 0$ gm. per 100 c.mm. (Haldane); C.I. 0.97; reticulocytes 1 per cent.; W.B.C. 10,800 per c.mm.; polymorphonuclear neutrophils 75 per cent., eosinophils 4.5 per cent.; basophils 1 per cent.; lymphocytes 12 per cent.; monocytes 6 per cent.; Türck cells 1.5 per cent. Subsequent examinations during treatment showed no significant reduction in the number of granular cells. Thrombocytes (direct method 3.8 per cent. citrate diluent) $20,000 \mathrm{c} . \mathrm{mm}$. Bleeding time (Duke) over 30 minutes.

On October 29, 1943, the coagulation time (Lee and White) was 11 minutes and the clot retraction (Macfarlane) 18 per cent. at 1 hour.

Capillary resistance. Positive pressure, tourniquet (Hess) test positive; negative pressure (Scarborough) $100 ; 100 ; 100$. These figures represent $\mathrm{mm}$. Hg suction required to produce a single petechia in each of three 'standard' areas of skin on the front of the forearm. They indicate a low capillary resistance.

Sternal puncture showed a reactive normoblastic bone marrow with excessive eosinophils and megakaryocytes. Thrombocytes were absent from all the marrow smears examined.

Repeated observations were made on the bleeding time (Duke method from the ear), thrombocyte count (direct method with 3.8 per cent. citrate diluent) and capillary resistance [negative pressure method of Scarborough (1941a)]. The results are plotted in the chart (fig. 1), the values for capillary resistance being given separately for each of the three 'standard' areas.

Progress AND TREATMENT. Epistaxis was temporarily controlled by packing the nose with gauze saturated with snake venom ('Stypven') and a transfusion of 1 pint of fresh blood given immediately into a vein. The next day there was gross haematuria, fresh epistaxis and further petechial haemorrhage and bleeding from the lips. The snake venom pack was renewed and a further pint of fresh blood transfused. Following this transfusion the temperature rose to $102 \cdot 8^{\circ} \mathrm{F}$. During the next four days the patient was transfused daily with half a pint of fresh blood and the nose was repacked at 

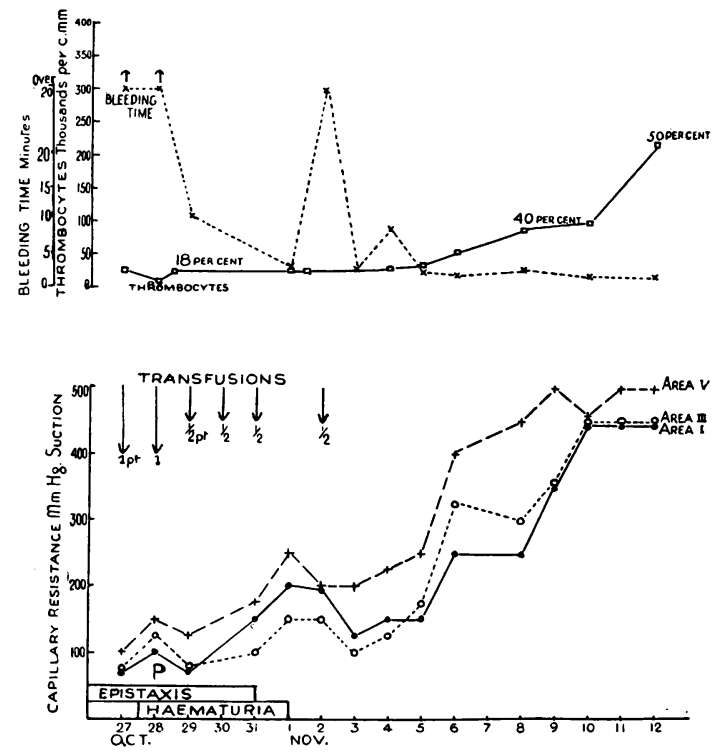

FIG. 1.-Record of bleeding time, thrombocyte count and capillary resistance (left arm) in A.M. with secondary thrombocytopenic purpura. $\mathbf{P}=$ purpura. Figures alongside record of thrombocyte count are values for clot retraction (Macfarlane's method).

intervals with gauze saturated with snake venom. Recovery was rapid after the fifth transfusion and no further treatment was required.

\section{Discussion}

The relationship between bleeding time, thrombocyte count, capillary resistance and the haemorrhagic manifestations is shown in fig. 1. During recovery from the bleeding phase, possibly as the result of repeated transfusion, the bleeding time fell and the capillary resistance increased, the thrombocyte count remaining below 50,000 per c.mm. On November 1, when bleeding ceased, the capillary resistance was double its initial values in all three standard areas and the bleeding time was 3 minutes. The platelets, however, were still under 50,000 per c.mm. The association of a normal bleeding time with a thrombocyte count below 50,000 per c.mm. is well known to occur in the course of thrombocytopenic purpura. Previous experience, confirmed in this case, indicates that this may be due to an increase in capillary resistance above the level which, in association with thrombocytopenia is responsible for the development of bleeding and suggests that the level of capillary resistance is a critical factor in the production of purpura and in determining the length of the bleeding time in this disease. During the non-bleeding phase of recovery (November 1-10) both bleeding time and capillary resistance had achieved satisfactory levels before the thrombocyte count reached 100,000 per c.mm. Thereafter the capillary resistance was maintained at a high level and the bleeding time below 5 minutes whilst the platelets gradually increased to 400,000 per c.mm. It has previously been reported (Scarborough, 1941b) in subjects normal in respect of bleeding time, coagulation time and thrombocyte count, that the extravascular suffusion of blood into the tissues, or into the alimentary canal is capable of producing a marked and immediate increase in capillary resistance. A similar result follows the intramuscular injection of blood and is also found within 6 hours after blood transfusion (Scarborough, 1941a). This phenomenon, which is striking, may also be observed in certain of the bleeding diseases, for example, in scurvy, haemophilia and hypoprothrombinaemia. In the present case the presence of the patient's blood under the skin and in the renal and alimentary tracts was not associated with an immediate increase in capillary resistance nor was this observed after any or all of the six blood transfusions, although, however, a gradual increase in capillary resistance in all three standard areas occurred during this period. It is suggested, therefore, that in this respect the behaviour of the capillaries in the bleeding phase was unusual. These observations tend to emphasize the importance of the vascular factor in the production of bleeding in thrombocytopenic purpura. In this connexion it is interesting to recall the observations of Macfarlane (1941) who was able to demonstrate by direct capillary microscopy in cases of thrombocytopenic purpura a defective capillary contractility.

The striking features of this case following the local application of sulphathiazole to the broken skin suggested that an attempt be made to investigate the effects, particularly on the capillaries, of the application of sulphathiazole to the intact skin under controlled conditions. Accordingly a 'test area' was marked out on the centre of the volar aspect of both forearms. On November 15 a piece of gauze 1 inch square covered with a layer of 5 per cent. sulphathiazole in eucerin was applied under strapping to an area of skin in the middle of the anterior surface of the right forearm for $1 \frac{1}{2}$ hours. Immediately following this application a significant reduction in capillary resistance was found in two out of three standard areas (one at the elbow and the other at the wrist) on the opposite (left) arm-A in fig. 2. The application of a similar patch for $1 \frac{1}{2}$ hours to the corresponding 'test area' on the left forearm on November 17 was immediately followed by a highly significant fall in capillary resistance in all three standard areas on the same (left) forearm-B in fig. 2-and a significant fall in capillary resistance in all three standard areas on the opposite (right) arm. By the next morning (18 to 20 hours later), on both occasions and in all areas, the capillary resistance had returned to the high level found before the test was made. Observation on the thrombocyte counts before and after these applications of sulphathiazole showed on the first occasion a fall of 95,000 per c.mm. and on the second a fall of 105,000 per c.mm., co-incident with the reduction in capillary resistance. It is possible that these differences may be significant also. On November 26 a 'patch test' of 5 per cent. sulphanilamide in eucerin was applied for $1 \frac{1}{2}$ hours to 

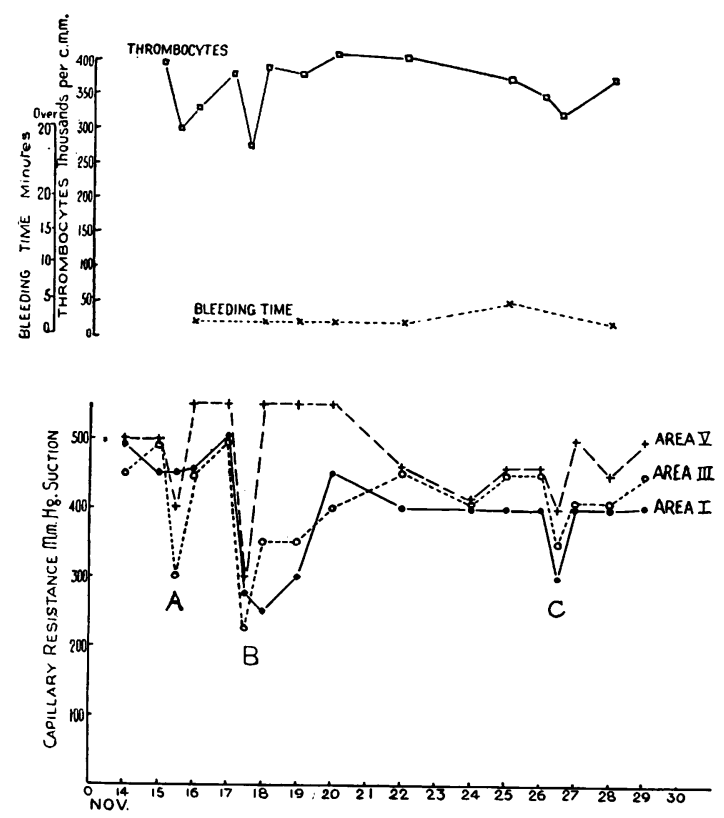

FIG. 2.-A continuation of fig. 1. At A, B and C. sulphonamide was applied to the unbroken skin. For further explanation see text.

the test area on the left arm. Six hours after its removal the capillary resistance was again found to be significantly reduced in all areas in both arms (C in fig. 2) but no significant alteration in platelet count was detected. Twenty-four hours later the capillary resistance had risen to the high level observed before the test.

Further evidence that the local application of sulphonamide drugs to the intact skin of the patient could produce a fall in capillary resistance was obtained by determinations of capillary resistance in the ' test areas' both before and after the application of the patch tests. The results with sulphathiazole and sulphanilamide are given in table 1 . In each case the application produced a marked fall in capillary resistance in the test area and also, though to a smaller extent, in the corresponding area on the other arm. A control test with eucerin alone produced no measurable effect. Similar experiments with three other subjects, two of whom had received sulphapyridine previously and one of whom (J. D.) had a level of capillary resistance considerably lower than the patient A. M. at the time he was tested all gave negative results even after the application of sulphonamide for 13 to 24 hours.

These experiments show that sulphonamides can be absorbed through the intact skin from a eucerin base in sufficient amount to produce effects upon the capillary walls of a ' sensitive' subject both at the site of application and in parts remote from it. It is not considered that unequivocal evidence of a reduction in thrombocyte count following the application has been obtained. Since there is no reason to suppose that the absorptive properties of the skin of the patient were in any way unusual, it is suggested that observations on capillary resistance after the application of similar patch tests, or even after oral administration might afford a means for detecting sulphonamide sensitivity. In this connexion it is interesting to recall the observations of Park (1943) who, writing of cutaneous hypersensitivity to sulphonamides, came to the conclusion that 'intradermal and patch tests were of little value in diagnosis.' Hurd and Jacox (1943) were also unable to demonstrate skin sensitivity in one of their cases which, however, was shown to be sensitive to sulphonamide by mouth. If these investigations are considered on a quantitative basis it is clear that the amount of sulphathiazole applied to the intact skin required during the experimental period to produce a fall in capillary resistance in A. M. was small - of the order of $0.05 \mathrm{gm}$. Furthermore the total amount of sulphathiazole applied to the broken skin which originally caused throm-

TABLE 1

OBSERVATIONS ON CAPILLARY RESISTANCE IN 'TEST' AREAS BEFORE AND AFTER PATCH TEST OF SULPHONAMIDE DRUGS

\begin{tabular}{|c|c|c|c|c|c|c|c|c|}
\hline \multirow{3}{*}{ Subject } & \multirow{3}{*}{ Date } & \multirow{3}{*}{$\begin{array}{c}\text { Test } \\
\text { Material }\end{array}$} & \multirow{3}{*}{$\begin{array}{l}\text { Time } \\
\text { applied } \\
\text { Hours }\end{array}$} & \multirow{3}{*}{$\begin{array}{l}\text { 'Test } \\
\text { arm }\end{array}$} & \multicolumn{4}{|c|}{ Capillary resistance in ' test' areas } \\
\hline & & & & & \multicolumn{2}{|c|}{ 'Test' arm } & \multicolumn{2}{|c|}{ Opposite arm } \\
\hline & & & & & Before & After & Before & After \\
\hline $\begin{array}{l}\text { Patient A.M. } \\
\text { Aged } 12 \\
\text { Control J.N. } \\
\text { Aged } 37 \\
\text { Control W.M. } \\
\text { Aged } 28 \\
\text { Control J.D. } \\
\text { Aged } 15\end{array}$ & $\begin{array}{l}17 \text { Nov. } \\
26 \text { Nov. } \\
28 \text { Nov. } \\
31 \text { Jan. } \\
1 \text { Feb. } \\
28 \text { Jan. } \\
29 \text { Jan. } \\
28 \text { Jan. } \\
30 \text { Jan. } \\
8 \text { Feb. } \\
9 \text { Feb. }\end{array}$ & $\begin{array}{l}\text { Sulphathiazole } \\
\text { Sulphanilamide } \\
\text { Eucerin } \\
\text { Sulphapyridine } \\
\text { Sulphapyridine } \\
\text { Sulphanilamide } \\
\text { Sulphathiazole } \\
\text { Sulphathiazole } \\
\text { Sulphathiazole } \\
\text { Sulphapyridine } \\
\text { Sulphanilamide }\end{array}$ & $\begin{array}{l}1 \frac{1}{2} \\
1 \frac{1}{2} \\
1 \frac{1}{2} \\
1 \frac{1}{2} \\
18 \\
1 \frac{1}{2} \\
13 \\
1 \frac{1}{2} \\
13 \\
18 \\
24\end{array}$ & $\begin{array}{l}\text { Left } \\
\text { Left } \\
\text { Left } \\
\text { Right } \\
\text { Left } \\
\text { Right } \\
\text { Left } \\
\text { Right } \\
\text { Left } \\
\text { Right } \\
\text { Left }\end{array}$ & $\begin{array}{l}500 \\
500 \\
400 \\
400 \\
500 \\
350 \\
450 \\
250 \\
300 \\
250 \\
300\end{array}$ & $\begin{array}{l}200 \\
250 \\
450 \\
350 \\
500 \\
450 \\
350 \\
350 \\
300 \\
250 \\
300\end{array}$ & $\begin{array}{l}300 \\
400 \\
300 \\
500 \\
350 \\
450 \\
300 \\
300 \\
200 \\
250 \\
250\end{array}$ & $\begin{array}{l}200 \\
250 \\
350 \\
500 \\
350 \\
450 \\
300 \\
300 \\
250 \\
250 \\
200\end{array}$ \\
\hline
\end{tabular}


bocytopenic purpura can hardly have exceeded one gramme. It was, therefore, considered unjustifiable to administer test doses of sulphonamide by mouth to this case. In the case of Hurd and Jacox (1943) thrombocytopenia originally occurred after the oral administration of $14 \mathrm{gm}$. of sulphathiazole in the treatment of pneumonia. After recovery small doses of both sulphathiazole and sulphadiazine ( 3 doses of $1.5 \mathrm{gm}$. of each) given by mouth were followed by an increase in bleeding time with a marked fall in thrombocyte count and a positive tourniquet test. Rosenfeld and Feldman (1942), however, gave a second course of sulphathiazole to a patient with renal calculus who initially developed thrombocytopenia after the administration of $5.5 \mathrm{gm}$. of sulphathiazole. No further purpura occurred. It would appear possible, therefore, that this type of sulphonamide sensitivity may be a temporary phenomenon.

The patient here described proved to be sensitive to the local application to the intact skin of both sulphathiazole and sulphanilamide and the patient of Hurd and Jacox was sensitive to both sulphathiazole and sulphadiazine administered by mouth. This serves to underline the already well-known fact that sensitivity is towards the sulphonamide group of drugs rather than towards any individual member of the group.

When taken together with the fatal case of purpura of the vascular type following sulphapyridine therapy reported by Sherlock and White (1944) in which the 'capillary resistance by a positive pressure method indicated very marked fragility, and in which 'the platelet count, although low $(120,000)$ had not been reduced to the level usually associated with bleeding in essential thrombocytopenic purpura,' these observations on the effect of sulphonamides on capillary resistance strongly suggest that it is the vascular factor which is of primary importance in the production of secondary thrombocytopenic purpura.

\section{Summary}

A case of symptomatic thrombocytopenic purpura in a boy, aged twelve years, is described following the local application of 5 per cent. sulphathiazole ointment for impetigo.

After return of the platelet count and capillary resistance to normal levels the application of sulphonamides to the intact skin produced striking reductions in capillary resistance at, and away from, the site of application. Less striking falls in platelet count were noted.

It is considered that these observations point to the importance of the vascular factor (low capillary resistance) as the basis of toxic thrombocytopenic purpura.

Thanks are due to Professor L. S. P. Davidson for permission to study the case and for his continued interest and advice throughout the investigation.

\section{REFERENCES}

Hurd, R. W., and Jacox, R. F. (1943). J. Amer. med. Ass., 122, 296.

Macfarlane, R. G. (1941). Quart. J. Med., 10, 1.

Park, R. G. (1943). Brit. med. J., 2, 69.

Rosenfeld, S., and Feldman, F. (1942). J. Amer. med. Ass., 118, 974.

Scarborough, H. (1941a). Edinb. med. J., 48, 550. (1941b). J. Physiol., 100, 5P.

Sherlock, S., and White, J. C. (1944). Brit. med. J., 2, 401 . 